\title{
Evaluation and treatment physiotherapeutic in pain syndrome patellofemoral: case study
}

\author{
Keyla Mara dos Santos', Tamiris Bepler Martins', Libak Abou', Juliete Palandi', Raysa Silva Venâncio',
} Géssica Maria Moreira'

\begin{abstract}
Introduction: The patellofemoral pain syndrome is a common condition in orthopedic practice, is defined as a pain or retropatellar in the absence of other diseases of the knee, multifactorial. Objectives: The aim of this study was to investigate the influence of a physiotherapy intervention in a patient with patellofemoral pain syndrome. Methods: We performed a descriptive study, through a case report with physical therapy assessment data and the description of the techniques used during treatment. Results: The results showed range of motion improves, the manifestations of pain and patellar mobility. Conclusion: The proposed physical therapy treatment given to this patient proved to be efficient, but a greater number of physical therapy sessions is required in order to obtain better results.

Keywords: patellofemoral joint; Patellofemoral pain syndrome; Treatment; Physiotherapy
\end{abstract}

\section{INTRODUCTION}

The patellofemoral pain syndrome (PFPS) is a common condition in orthopedic practice ${ }^{(1)}$ is defined as an anterior or retropatellar pain in the absence of other diseases of the knee, multifactorial etiology ${ }^{(2)}$, affecting mainly young adults and athletes. Its incidence varies from 10 to $40 \%$ occurring frequently in women than in men ${ }^{(3)}$. Its etiology is unknown, but the imbalance of power between the main dynamic stabilizers of the joint (vastus medialis oblique (VMO) and vastus lateralis) is considered the pre-eminent factor in the onset of symptoms ${ }^{(1,4)}$. In addition, poor leg alignment, imbalance of the extensor musculature, insufficiency of VMO, weak hip muscles, excessive activity and incongruity between the patella and the trochlear sulcus femoral as contributing factors to the syndrome onset ${ }^{(4,5,8)}$.

The study by Ribeiro et al. (2010)(14), shows that patients with PFPS have higher electrical activity of the vastus lateralis muscle, an increase in the groove angle and decrease the congruence angle in relation to the control group, achieving greater patellar instability. The pain is usually of insidious onset ${ }^{(12)}$ and intensified after performing activities like running, squat, go up and down stairs or hills, long remain sitting or getting up from a sitting position ${ }^{(13)}$.

Conservative treatment is the most appropriate ${ }^{(1,5)}$ and its principle is the selective strengthening of the VMO muscle and re-education of motor control of the patellar stabilizing muscles, aiming at restoring joint stability ${ }^{(4,5,13)}$. Muscle stretching exercises, especially the global, must be indicated in the treatment of patients with PFPS, for an effective reduction of pain, and enable a better realignment of knees and increase flexibility, which may facilitate muscle strengthening ${ }^{(2)}$.

In view of this, the aim of this study was to verify the influence of a physiotherapeutic intervention on a patient with Patellofemoral Pain Syndrome.

\section{METHODS}

A descriptive study was conducted, through a case report, with data from the physiotherapy evaluation and description of the techniques used during the treatment. The present study is approved by the Research Ethics Committee under number $789,272 / 2014$.

\section{Case report}

A 31-year-old female patient with clinical diagnosis of bilateral patellofemoral pain syndrome. The patient was a volleyball on the court player since her 15 years old, and when she started playing sand volleyball, the symptoms of anterior knee pain began. Pain is not continuous, located on patella sides and the lower face of both the right and left lower limbs. During the evaluation, the patient reported exacerbation of pain in the left knee when walking and in the right knee when remaining large periods in the sitting position and difficulty to perform activities which require excessive 
knee flexion. During physical examination, it was observed some postural alterations such as hyperextension in the left lower limb, flexion of the right knee, right foot in external rotation and inversion, and incorrect hip alignment, with the anterior superior iliac spine (ASIS) being higher than the right. There was a difference of $1 \mathrm{~cm}$ in the lower limbs and increased $Q$ angle. Pain on palpation of the patellar tendon and the vastus lateralis muscle bilaterally. The mobility exam showed a decrease in the range of motion of the left ankle, especially when performing dorsiflexion. Special tests, patellar compression to identify patellofemoral instability and Clark's signal, for patellofemoral dysfunction, were considered positive.

Physiotherapy started 2 months after the onset of the pain symptoms, being performed twice a week with a duration of 50 minutes each. There were 9 meetings which occur in the Physiotherapy School Clinic of the Health and Sports Science Center of the State University of Santa Catarina. In the first meeting the physiotherapy evaluation was carried out and in the last one was the reevaluation, totaling 7 physiotherapy sessions.

For the assessment of range of motion, it was used a goniometer of Carci brand, in transparent plastic with 2 rules for measurement of joint amplitude, with a transfer system from 0 o to 360 ㅇ․

For the evaluation of Perimetry, a tape measure of 1.5 meters was used, and the measurements of the circumference were made in $5,10,15$, and $20 \mathrm{~cm}$ of the reference point above and infra-joint.

For the evaluation of muscle strength, the Kendall scale et al. (1995) was used, where the muscular strength may be graded as follows: 0 : null, absence of contraction; 1 : sketch, slight contraction but unable to produce movement: 2 : weak, there is movement only in the absence of gravity; 3: regular, it can achieve movement overcoming gravity; 4: good, it can perform movement and also some external resistance and 5: normal, it can achieve movement overcoming great resistance.

The visual analog pain scale was used for the evaluation of pain, where 0 means total absence of pain and 10 the maximum level of pain which it is bearable by the patient.

In view of the observed results during evaluation, the following short-term goals were outlined: to reduce pain complaints, to strengthen the active stabilizers of the knee joint (vastus lateralis, vastus medialis, vastus medialis and rectus femoris), to improve flexibility of the lower limbs, improve range of motion of the left ankle (dorsiflexion), recruiting the vastus oblique medial muscle because it is the main joint medial stabilizer. And the following long-term goals: to promote a better hip alignment, restore proper movement and neuromuscular control, provide a gradual return to function. The used pipelines during treatment are shown in Table 1:
Table 1. Description of used pipelines during the physiotherapy

\begin{tabular}{|c|c|c|}
\hline & Exercises & Description \\
\hline 1) & Patellar mobilization & $\begin{array}{l}\text { Performed passively with the patient } \\
\text { in supine position with a roll below the } \\
\text { knees, aiming to increase the production } \\
\text { of the synovial fluid and decrease the } \\
\text { pain. Movements to lateral, medial, } \\
\text { superior and inferior for } 2 \text { minutes. }\end{array}$ \\
\hline 2) & $\begin{array}{l}\text { Deep transverse massage } \\
\text { in the patellar tendon }\end{array}$ & $\begin{array}{l}\text { Performed passively with the patient in } \\
\text { dorsal decubitus and a roll below the } \\
\text { knees, aiming to decrease and prevent } \\
\text { adhesions. }\end{array}$ \\
\hline 3) & Cryotherapy & $\begin{array}{l}\text { The patient was instructed to do at } \\
\text { home, as soon as physiotherapy sessions } \\
\text { finish or in exacerbated pain, during } \\
15 \text { to } 30 \text { minutes. }\end{array}$ \\
\hline 4) & $\begin{array}{l}\text { Strengthening of } \\
\text { quadriceps in closed } \\
\text { kinetic chain }\end{array}$ & $\begin{array}{l}\text { Squatting at } 45^{\circ} \text { of knee flexion and mini } \\
\text { squats with displacement. There were } \\
3 \text { sets of } 10 \text { repetitions or } 10 \text { laps in a } \\
5 \text { meter runner. }\end{array}$ \\
\hline 5) & $\begin{array}{l}\text { Range of motion exercises } \\
\text { for dorsiflexors }\end{array}$ & $\begin{array}{l}\text { The patient actively performed } \\
\text { dorsiflexion movement followed by } \\
\text { plantarflexion in } 3 \text { sets of } 10 \text { repetitions } \\
\text { or, more playfully, drew the alphabet with } \\
\text { her feet in the air. }\end{array}$ \\
\hline 6) & $\begin{array}{l}\text { Joint mobilization of the } \\
\text { ankle }\end{array}$ & $\begin{array}{l}\text { Performed passively with the patient in } \\
\text { the supine position. }\end{array}$ \\
\hline 7) & Iliotibial stretching & $\begin{array}{l}\text { Active, supported on a wall, holding for } \\
1 \text { minute. }\end{array}$ \\
\hline 8) & $\begin{array}{l}\text { Lateral retinaculum } \\
\text { stretching }\end{array}$ & $\begin{array}{l}\text { Passively with the patient in dorsal } \\
\text { decubitus with a roll below the knees, } \\
\text { holding for } 1 \text { minute. }\end{array}$ \\
\hline 9) & $\begin{array}{l}\text { Hamstrings and Sural } \\
\text { Triceps stretching }\end{array}$ & $\begin{array}{l}\text { Passively or actively in dorsal decubitus } \\
\text { with theraband or standing on a } 20 \mathrm{~cm} \\
\text { high ramp, holding for } 1 \text { minute. }\end{array}$ \\
\hline & $\begin{array}{l}\text { Anteversion and Pelvic } \\
\text { Retroversion Exercises }\end{array}$ & $\begin{array}{l}\text { Made in the Swiss ball, } 3 \text { sets of } \\
20 \text { repetitions. }\end{array}$ \\
\hline & $\begin{array}{l}\text { Strengthening of vastus } \\
\text { medialis and vastus } \\
\text { lateralis in open kinetic } \\
\text { chain }\end{array}$ & $\begin{array}{l}\text { Performed with theraband resistance, } \\
3 \text { sets of } 10 \text { repetitions. }\end{array}$ \\
\hline
\end{tabular}

With one-sided support on the

12) Proprioceptive training proprioceptive disc and aid of a mirror for better body awareness.

During the performed exercises, there was no pain. If the patient reported pain, the difficulty of the activity was reduced. Guidance was also given for realization of the exercises at home.

\section{RESULTS}

Table 2 shows the improvement in the range of motion achieved after treatment. The change from 50 to 0 o in the extension of the right knee may have caused a decrease of the knee flexion presented in the first evaluation. In addition, 10 o of left ankle dorsiflexion were gained, which will lead to improvement of the patient's gait. 
In Table 3, there are the values of lower limbs perimetry, it is observed in general, the increase in the measures values which is related to hypertrophy, due to the lower limb strengthening training. However, some values decreased and may be justified by small edema or accumulation of fluid in the region on the first evaluation.

The results of the special tests were the same at the beginning and end of the treatment, except the passive tilt test, which evaluates the passive amplitude of the patellar tilt. Inclinations less than 15으 may lead to patellofemoral pain, therefore, it is possible that the patient improved her patellar mobility (Table 4).

Regarding muscle strength, the patient presented grade 5 (Kendall, 1995) in all tests performed, however in the first evaluation of the vastus lateralis muscle force test, the patient

Table 2. Knee and ankle range of motion measures performed by using a goniometer.

\begin{tabular}{|c|c|c|c|c|c|}
\hline \multirow{2}{*}{ Articulation } & \multirow{2}{*}{ Movement } & \multicolumn{2}{|c|}{ Pre-treatment } & \multicolumn{2}{|c|}{ Post-treatment } \\
\hline & & Right & Left & Right & Left \\
\hline Knee & Flexion & $132 \circ$ & $132^{\circ}$ & 1350 & 135 응 \\
\hline Knee & Extension & 50 & $0 ㅇ$ & 0음 & 0 은 \\
\hline Ankle & Plantarflexion & $90 \circ$ & 70 & $90 \circ$ & $80 ㅇ$ \\
\hline Ankle & Dorsiflexion & 10 & 0 은 & 10 & 10 은 \\
\hline
\end{tabular}

Table 3. Circumference Measurements of the lower limbs obtained by Perimetry.

\begin{tabular}{|c|c|c|c|c|c|}
\hline & \multirow{2}{*}{ Lower Limbs } & \multicolumn{2}{|c|}{ Pre-treatment } & \multicolumn{2}{|c|}{ Post-treatment } \\
\hline & & Right & Left & Right & Left \\
\hline \multirow{5}{*}{ Upper } & $20 \mathrm{~cm}$ & 56 & 58 & 56.5 & 57 \\
\hline & $15 \mathrm{~cm}$ & 51 & 54 & 51 & 49 \\
\hline & $10 \mathrm{~cm}$ & 47 & 49 & 46 & 47 \\
\hline & $05 \mathrm{~cm}$ & 42 & 42.5 & 42.5 & 43 \\
\hline & Zero point & 39 & 39 & 39.5 & 39.5 \\
\hline \multirow{4}{*}{ Lower } & $05 \mathrm{~cm}$ & 36 & 37 & 37.5 & 37.5 \\
\hline & $10 \mathrm{~cm}$ & 38 & 39 & 38 & 40 \\
\hline & $15 \mathrm{~cm}$ & 36.5 & 38.5 & 37.5 & 39 \\
\hline & $20 \mathrm{~cm}$ & 34 & 33.5 & 33 & 35 \\
\hline
\end{tabular}

felt pain during the requested movement, and in the last evaluation there were no pain complaints (Table 5).

There was also a decrease in pain and an improvement in the functionality, since the patient exacerbated her pain when walking, remaining in the sitting position and squatting and after treatment, the situation occurs only when squatting (Figure 1).

\section{DISCUSSION}

The conservative treatment of PFPS through kinesiotherapy aims to promote a balance among the portions of the quadriceps muscle, through its open kinetic chain (OKC) and closed kinetic chain (CKC) exercises, the medial patellar stabilizers (VMO) and lateral (vastus lateralis obliquus (VLO) and vastus lateralis longus (VLL)) which are essential in maintaining the patellar alignment, thus relieving the symptoms of this syndrome $e^{(1,2,4,8,11)}$.

Muscle shortening is one of the PFPS etiological factors, stretching exercises have as a benefit the increased flexibility and improved performance, however, it has not been used in the treatment of PFPS ${ }^{(2.5)}$. A study aimed at comparing the efficacy of muscle stretching on the functional recovery of patients with PFPS. Twenty women with PFPS were selected, divided into two groups: group 1 (G1) performed stretching of the posterior chain muscles by the technique of Global posture re-education (GPR) and group 2 (G2) segmental stretching of

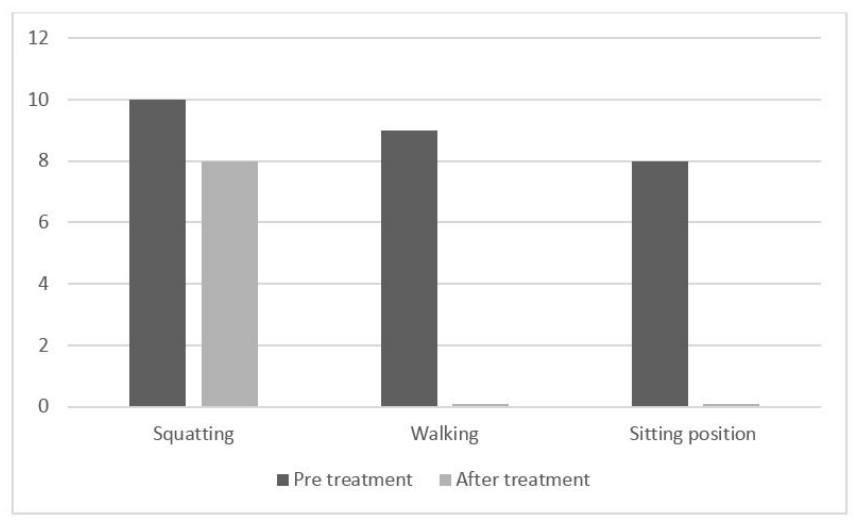

Figure 1. Values of the visual analog scale of pain in relation to movements that cause pain exacerbation of the patient pre- and post-treatment.

Table 4. Special tests results in the first and last evaluation.

\begin{tabular}{|c|c|c|c|c|c|}
\hline \multirow{2}{*}{ Special test } & \multirow{2}{*}{ Goal } & \multicolumn{2}{|c|}{ Pre-treatment } & \multicolumn{2}{|c|}{ Post-treatment } \\
\hline & & Right & Left & Right & Left \\
\hline Patellar compression & Patellofemoral instability & Positive & Positive & Positive & Positive \\
\hline Clarke's Sign & Patellofemoral dysfunction & Positive & Positive & Positive & Positive \\
\hline Seizure & Lateral patellar dislocation & Negative & Negative & Negative & Negative \\
\hline Lateral displacement & $\begin{array}{c}\text { Action of the quadriceps on } \\
\text { patellar displacement }\end{array}$ & Negative & Negative & Negative & Negative \\
\hline Passive Patellar Tilt & Passive amplitude of the patella & Positive & Positive & Negative & Negative \\
\hline
\end{tabular}


Table 5. Muscle strength tests

\begin{tabular}{ccc}
\hline Muscle & Pre-treatment & Post-treatment \\
\hline Vastus lateralis & 5 & 5 \\
Vastus medialis & 5 & 5 \\
Rectus femoris & 5 & 5 \\
Hamstrings & 5 & 5 \\
\hline
\end{tabular}

(Kisner, 2000).

the hamstring and gastrocnemius muscles. The group which underwent stretching by the GPR technique showed more significant improvements in relation to pain intensity and greater gains in flexibility. It may be suggested, therefore, that stretching exercises, especially the GPR, should also be indicated in the treatment of patients with PFPS. Moreover, the treatment also allowed greater knee realignment (reduction of the $\mathrm{Q}$ angle), and increased flexibility, which may facilitate muscle strengthening ${ }^{(2)}$. In the present study, only the segmental stretches were performed and there were no changes in relation to the $\mathrm{Q}$ angle, however the number of physiotherapy sessions performed may not have been sufficient for this gain.

Fehr et al, 2008 ${ }^{(15)}$ analyzed the therapeutic effects of OKC and CKC in the treatment of PFPS. Twenty-four volunteers with PFPS were randomly divided into two groups: group I $(n=12)$ : performed exercises in OKC; Group II ( $n=12)$ : performed exercises in CKC. Analysis of VMO/VL ratio values in groups I and II showed no significant differences between pre- and post-treatment times in the concentric $(p>0.05)$ and eccentric ( $p>0.05$ ) phases in OKC and CKC.

In this study, CKC of squatting exercise was chosen because it was more functional than OKC exercises. These exercises also provide greater stability through co-contraction of the quadriceps and hamstring muscle and joint proprioception ${ }^{(4.13)}$. In addition, the weight bearing facilitates the action of the VMO in CKC exercises compared to OKC exercises ${ }^{(10)}$.

The imbalance between the VMO and VL muscles has been placed as one of the etiological factors of the patellofemoral joint changes. From this, Domingues et al. $2008^{(6)}$ studied a way to selectively activate the VMO through active kinesiotherapy and the end of their study, they concluded that selective activation of the VMO was not detected in any of the exercises proposed by the literatures.

A structural review of the literature, reviewed publications of the last twelve years in the main scientific databases on PFPS treatment. Twenty-two studies reviewed, twelve described mainly the strength training of lower limb muscles, which is the most common and effective physiotherapeutic practice in the treatment of PFPS, with emphasis on open and closed kinetic chain exercises. However other physiotherapy methods should not be discarded, because the success of these has also been demonstrated and scientifically proven ${ }^{(3)}$.

\section{CONCLUSION}

The proposal of the physiotherapeutic work presented to this patient proved to be efficient, however a greater number of physiotherapy sessions are necessary to obtain better results. It was observed improvement in pain and functional complaints, as well as improvement in range of motion and patellar mobility in the post-treatment. As a case study, does not allow generalization of the observed results.

\section{AUTHOR'S CONTRIBUTION}

Keyla Mara dos Santos: design and research project planning and data collection. Tamiris Bepler Martins: design and planning of the research project, writing and critical review. Libak Abou: writing and critical review and data interpretation. Libak Abou: writing and critical review and data interpretation. Juliete Palandi: analysis and data interpretation. Raysa Silva Venâncio e Gessica Moreira: data analysis and final writing.

\section{CONFLICTS OF INTEREST}

There is no conflict of interest

\section{REFERENCES}

1. Bevilaqua-Grossi D, Felicio RL, Simões R, Coqueiro KRR, Monteiro-Pedro $\mathrm{V}$, et al. Sindrome da dor femoropatelar. Jornal Livre, Ribeirão Preto, 16 jun. 2008. Disponível em: <http://www.jornallivre.com.br/31037/ sindrome-da-dor-femoropatelar.html>. Acesso em: 12 abr. 2014.

2. Cabral CMN, Yumi C, Sacco ICN, Casarotto RA, Marques AP. Eficácia de duas técnicas de alongamento muscular no tratamento da síndrome femoropatelar: um estudo comparativo. Fisiterapia e Pesquisa 2007;14(2):48-56.

3. Campos IRM, Sales ANS, Martins AGV, Santos DF, Barbosa DA, Aguiar JBC, et al. Tratamento fisioterapêutico na síndrome da dor patelofemoral: uma revisão da literatura. Revista Movimenta 2013;6(3):1984-4298.

4. Hott, A, Liavaag S, Juel NG, Brox JI. Study protocol: a randomised controlled trial comparing the long term effects of isolated hip strengthening, quadriceps-based training and free physical activity for patellofemoral pain syndrome (anterior knee pain). BMC Musculoskeletal Disorders, [s.I.], 2015;16(1):40-48. Springer Science + Business Media. http://dx.doi.org/10.1186/s12891-015-0493-6.

5. Ferber R, Bolgla L, Earl-Boehm JE, Emery C, Hamstra-Wright K. Strengthening of the Hip and Core Versus Knee Muscles for the Treatment of Patellofemoral Pain: A Multicenter Randomized Controlled Trial. Journal of Athletic Training. 2015;50(4):366-377.

6. Domingues CB. Ativação seletiva do vasto medial por meio da cinesioterapia ativa. Fisioterapia em Movimento 2008;21(1):21-31.

7. Neto MG. Aplicação e efeitos da cinesioterapia em indivíduos com síndrome da dor femoropatelar. Revista Científica da Unirb 2011;17(5,):95-101.

8. Gramani-Say, K, Pulzatto F, Santos GM, Vassimon-Barroso V, Oliveira S, Bevilaqua-Grossi $D$, et al. Efeito da rotação do quadril na síndrome da dor femoropatelar. Rev. bras. fisioter. 2006;10(1).

9. Harrison E, Magee D. Patellofemoral pain syndrome: the ongoing challenges in etiology, diagnosis, and management. Critical Reviews in Physical and Rehabilitation Medicine. 2001;13(2):253-68.

10. Hodges PW, Richardson CA. The influence of isometric hip adduction on quadriceps femoris activity. Scandinavian Journal Rehabilitation 1993; 25: 57-62.

11. Kettunen JA1, Harilainen A, Sandelin J, Schlenzka D, Hietaniemi K, Seitsalo $S$, et al. Knee arthroscopy and exercise versus exercise only for chronic. BMC Medicine, 2007;13(5):38. 
12. Leite, C. Eficácia de um treinamento neuromuscular na intensidade da dor e na incidência da síndrome da dor femoropatelar entre dançarinos. R. Ci. Méd. Biol., 2006;5(1):55-62.

13. Pulzatto, F. Atividade elétrica dos músculos estabilizadores da patela em indivíduos portadores da síndrome da dor femoropatelar durante exercícios realizados no steep. Dissertação de mestrado. Ufscar. 2010, p.1-89.
14. Ribeiro, ACS. et al. Avaliação eletromiográfica e ressonância magnética do joelho de indivíduos com síndrome da dor femoropatelar. Revista Brasileira de Fisioterapia, 2010;14(3):221-228.

15. Santos GM, Say KG, Pulzato F, Oliveira AS, Bevilaqua-Grossi D, Monteiro-Pedro V. Relação eletromiográfica integrada dos músculos vasto medial oblíquo e vasto lateral longo na marcha em sujeitos com e sem síndrome de dor femoropatelar. Revista Brasileira de Medicina do Esporte 2007;13(1):17-21. 